\title{
Managing for climate change on federal lands of the western United States: perceived usefulness of climate science, effectiveness of adaptation strategies, and barriers to implementation
}

\author{
$\underline{\text { Kerry B. Kemp }}^{1}, \underline{\text { Jarod J. Blades }}^{2}, \underline{\text { P. Zion Klos }}^{1}, \underline{\text { Troy E. Hall }}^{3}, \underline{\text { Jo Ellen Force }}^{1}, \underline{\text { Penelope Morgan }}^{1}$ and Wade T. Tinkham ${ }^{4}$
}

\begin{abstract}
Recent mandates in the United States require federal agencies to incorporate climate change science into land management planning efforts. These mandates target possible adaptation and mitigation strategies. However, the degree to which climate change is actively being considered in agency planning and management decisions is largely unknown. We explored the usefulness of climate change science for federal resource managers, focusing on the efficacy of potential adaptation strategies and barriers limiting the use of climate change science in adaptation efforts. Our study was conducted in the northern Rocky Mountains region of the western United States, where we interacted with 77 U.S. Forest Service and Bureau of Land Management personnel through surveys, semistructured interviews, and four collaborative workshops at locations across Idaho and Montana. We used a mixed-methods approach to evaluate managers' perceptions about adapting to and mitigating for climate change. Although resource managers incorporate general language about climate change in regional and landscape-level planning documents, they are currently not planning on-the-ground adaptation or mitigation projects. However, managers felt that their organizations were most likely to adapt to climate change through use of existing management strategies that are already widely implemented for other non climate-related management goals. These existing strategies, (e.g., thinning and prescribed burning) are perceived as more feasible than new climate-specific methods (e.g., assisted migration) because they already have public and agency support, accomplish multiple goals, and require less anticipation of the future timing and probability of climate change impacts. Participants reported that the most common barriers to using climate change information included a lack of management-relevant climate change science, inconsistent agency guidance, and insufficient time and resources to access, interpret, and apply current climate science information to management plans.
\end{abstract}

Key Words: adaptation; Bureau of Land Management; climate change; decision making; Forest Service; land management; public lands

\section{INTRODUCTION}

In the U.S. northern Rocky Mountain region, the United States Forest Service (USFS) and the Bureau of Land Management (BLM) are responsible for managing public lands that account for roughly 13 million hectares in Idaho and 11 million hectares in Montana (Gorte et al. 2012). Climate change is likely to impact the forests and rangelands managed by these agencies and alter important ecosystem services such as fresh drinking water sources, recreation, and timber production, all of which are integral to local communities and economies (e.g., Pederson et al. 2006). Therefore, how these agencies adjust their current management practices to adapt to and mitigate the impacts of climate change will be an important aspect of future land management.

Federal agencies have emphasized climate change within planning and management at the national level for several years. In 2008, the USFS acknowledged the role climate change has played in changing wildfire regimes, bark beetle infestations, and water availability: "Without fully integrating consideration of climate change impacts into planning and actions, the Forest Service can no longer fulfill its mission" (Dillard et al. 2008:2). The USFS highlighted two strategies for addressing climate change impacts on national forests: facilitated adaptation (i.e., actions for reducing the negative impacts of climate change) and mitigation (i.e., actions to reduce emissions and enhance natural carbon sequestration; Dillard et al. 2008, Cruce and Holsinger 2010).
Additionally, the USFS created the Climate Change Performance Scorecard, which was intended to help units within the agency implement short-term initiatives and long-term investments in response to projected impacts of climate change, as well as track their progress toward these goals (Tkacz et al. 2010). Likewise, the BLM has had a strategy for responding to climate change in place since 2001, although potentially less targeted than the guidance put forth by the USFS (Ellenwood et al. 2012). Furthermore, as part of Secretarial Order No. 3289, in 2009 the Department of the Interior established several Climate Science Centers and Landscape Conservation Cooperatives to address informational concerns and anticipated challenges the Department of the Interior may face in managing for the impacts of climate change (GAO 2007). Presidential executive orders issued in 2009 (President of the United States 2009) and 2013 (President of the United States 2013) also provided uniform policy guidance aimed at encouraging climate change adaptation and carbon mitigation within all federal agencies.

Although federal mandates are in place, addressing climate change at regional (i.e., unit/forest/watershed) and local (i.e., field office/district/stand) levels presents numerous challenges, especially within impact assessments designed for long-term land use planning or specific management projects. These challenges include both internal and external factors, such as a lack of agency direction (Archie et al. 2012), insufficient time and funding allocated for implementing new programs, litigation by external

${ }^{1}$ Department of Forest, Rangeland, and Fire Sciences, University of Idaho, ${ }^{2}$ College of Food, Agriculture, and Environmental Science, University of Wisconsin-River Falls, ${ }^{3}$ Department of Forest Ecosystems and Society, Oregon State University, ${ }^{4}$ Department of Forest and Rangeland Stewardship, Colorado State University 
interest groups (Lachapelle et al. 2003, Jantarasami et al. 2010, Wright 2010), and negative public perceptions (Archie et al. 2012, Archie 2014). Transferring science between research and management can also be a challenge. Managers often lack time to review relevant literature (Kocher et al. 2012), and a dearth of information at management-relevant scales can impede the use of existing science (Archie et al. 2012). For example, resource managers have repeatedly expressed a need for downscaled climate change projections to match the scales at which land management is accomplished (e.g., Jantarasami et al. 2010, Archie et al. 2012).

Climate change may also dictate that land managers consider novel approaches to land management to achieve their goals. Rangeland and forest management in the western United States often emphasizes evaluating current conditions against historical reference conditions and using the estimates of the degree of ecosystem change to prioritize different types of treatments (Keane et al. 2009, Caudle et al. 2013). The extent of change from past decades and centuries, coupled with predicted future changes, suggests that adaptive management approaches that consider a wide range of different options may be necessary to effectively carry out the provisions highlighted in agency policies for climate change (Hobbs et al. 2014).

Although climate change has been highlighted as an important management priority at the federal level, it is still uncertain how climate change science is being considered in project management and planning by local resource managers. Our research addresses how federal land management agencies in the U.S. northern Rocky Mountains are currently utilizing or thinking about applying climate change science to management activities. Specifically, we asked USFS and BLM managers how climate change science is useful for their work and whether they as individuals, or their agencies, are currently incorporating this information into land management planning. Additionally, we asked what management actions they see as effective for adapting to, or mitigating, climate change and if their agencies are considering implementation of these actions. Finally, if managers are not addressing climate change in their planning efforts as suggested by the policy directives, what barriers do the managers perceive as impeding their use and incorporation of the science into management? Understanding the challenges resource managers perceive and the techniques they are using to adapt to the impacts of climate change will help to highlight the types of information, policies, and directives that can better aid managers in incorporating climate change science into management.

\section{METHODS}

We used a series of different approaches, including quantitative surveys, semistructured interviews, and one-day workshops, to understand managers' perceptions about the usefulness of climate change science, efficacy of potential adaptation strategies, and barriers to implementation of adaptation and mitigation measures. Survey and interview input was collected from study participants both before and after the workshops as part of a larger study to track individual changes in perceptions about climate change science (Blades 2013). We aggregated individual responses from the surveys, interviews, and workshop discussions to focus on general tendencies and insights across participants, drawing on pre- and postworkshop responses that bear on our research questions when appropriate, rather than analyzing individual changes from before to after the workshops.

The vast majority ( $>90 \%$ ) of federal lands in Idaho and Montana are managed by the USFS and the BLM, and these lands account for approximately $62 \%$ and $29 \%$, respectively, of the land base of these two states (Gorte et al. 2012). Therefore, we elected to focus the majority of our recruitment efforts on individuals from the USFS and the BLM, although other federal (e.g., the U.S. Fish and Wildlife Service, the National Park Service, the National Oceanic and Atmospheric Administration), tribal, and state resource managers were invited to participate in our workshops. Participants who were likely to actively make or implement land management decisions and whose agency experience would give them the ability to comment in depth on land management and climate change directives were purposely selected through public contact lists for the study. These participants were planners, ecologists and biologists, silviculturists, fire managers, and water resources managers. After the initial selection of participants, a snowball sampling approach was used in which individuals who agreed to participate were asked to identify other interested individuals or coworkers who would have knowledge of how agencies address climate change. We initially recruited 257 individuals to participate in the workshops, however; only 97 individuals elected to participate, for a $38 \%$ response rate. Of those 97 individuals, 77 were federal land managers from the USFS ( $n$ =66) and the BLM $(n=11)$. All participants who signed up for the workshops were sent preworkshop surveys, and a random sample of those responding to the surveys were asked for interviews. We elected to exclude individuals from other state and federal agencies because of the overall poor response rate from these agencies. We aggregated USFS and BLM responses for all phases of data collection based on the small representation by BLM employees. Both the USFS and the BLM are mandated to manage for multiple uses and sustained yields, and although these specific uses may differ slightly (e.g., timber harvest versus cattle grazing and mining), many are similar (e.g., recreation, wildlife, water; Gorte et al. 2012). Likewise, both agencies must allow public participation in the planning process and address potential environmental impacts as part of the National Environmental Policy Act of 1969.

We conducted our one-day workshops in four locations across the northern Rocky Mountains in November 2012 (Fig. 1). The locations represented five national forests and two BLM districts (Fig. 1). Representatives of several collaborative organizations and nonprofit groups who actively work with individuals from the USFS and the BLM participated in the workshops, but we focused specifically on federal resource managers' responses. During each eight-hour workshop, we presented historical information and future projections about climate change impacts at global, regional, and local scales. Most of the regional- and local-scale projections focused on changes in the northern Rocky Mountain region for resources of interest, including hydrology, forest species distributions, and wildfire activity. At the end of each presentation, workshop participants were assigned to small groups chosen to represent the mix of agencies, organizations, and specializations present. During these breakout discussions, participants were asked to reflect on how climate change information could be useful in their work and the management implications of the information presented. Discussions were 
facilitated in a manner that gave all participants an opportunity to speak openly about their personal perceptions, as well as to express opinions on behalf of their agencies. Main discussion points that arose during the conversations were recorded on flip charts by trained facilitators.

Fig. 1. Map of the study area highlighting the National Forests (dark green) and Bureau of Land Management (BLM) districts (light yellow) represented by workshop participants. Participants were from six national forests and two BLM districts. The majority of land area in the U.S. northern Rocky Mountains (defined here as Idaho and western Montana) is federal land under the control of the US Forest Service (light green) and BLM (bright yellow).

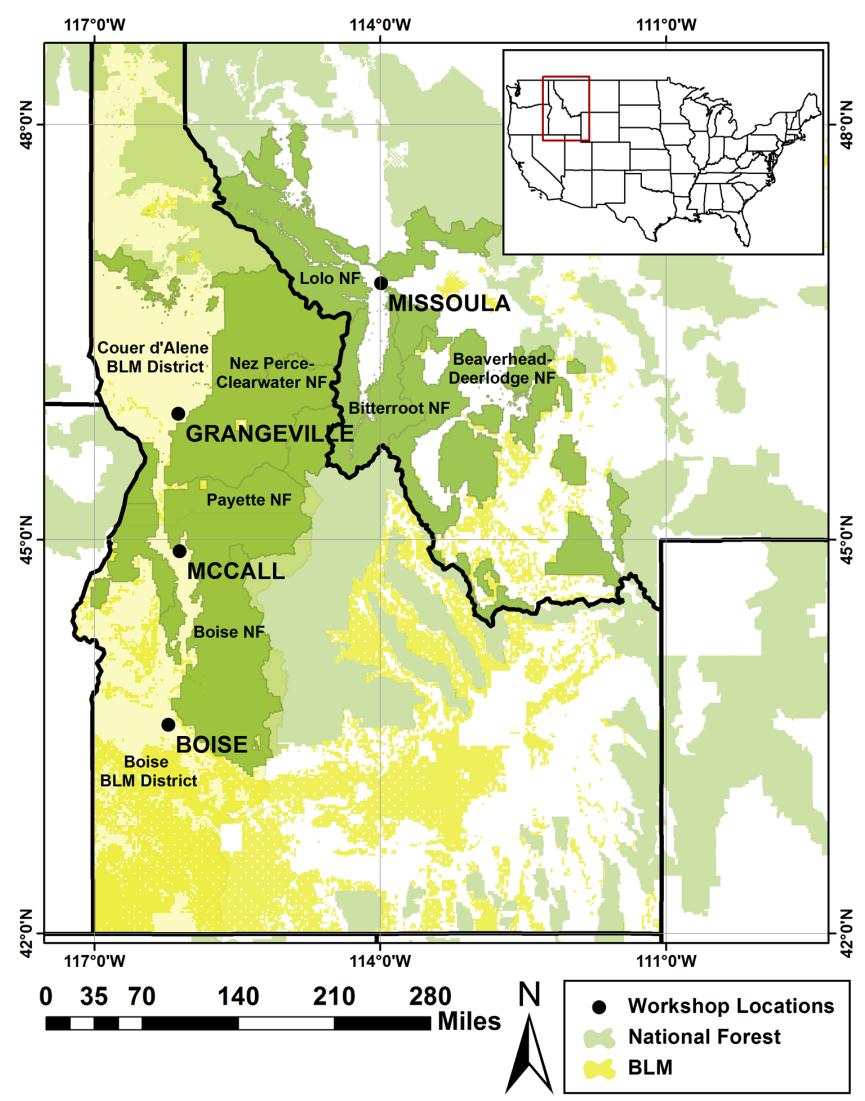

Online surveys were sent to all workshop participants via email prior to and immediately following the workshops. If participants had not completed an online survey prior to arriving at the workshop, they were asked to fill out a paper copy on arrival. Quantitative survey responses were made on a 7-point Likert-type scale from -3 (strongly disagree) to +3 (strongly agree), and descriptive statistics were summarized using SPSS version 13 (SPSS 2010). When survey questions were asked both before and after the workshops, we present the results of only the preworkshop data because we believe these data most closely reflect perceptions of the broader population of resource managers who did not participate in workshop presentations, discussions, or conversations. Several of the postworkshop survey questions explicitly asked participants about the perceived usefulness of information at varying spatial scales (i.e., global, regional, and local); we compared these ratings using one-way analysis of variance.

Preworkshop interviews were conducted by phone in late October and early November 2012. Questions during the preworkshop interviews covered a range of topics related to perceptions of climate change and impacts, including credibility and salience of climate change science, perceived vulnerability to and severity of climate change impacts, and individual and collective management responses (Blades 2013). However, for the purposes of this analysis, we only included responses regarding the current use of climate change science, potential actions for adapting to and mitigating the effects of climate change, and barriers to using climate change science within management organizations (Appendix 1). All interview questions were open-ended, allowing for a range of responses, and interviewers asked follow-up questions to clarify responses. Postworkshop interviews were conducted by phone in December 2012 and January 2013 and generally covered the same topics as the preworkshop interviews, but also included evaluative components targeted to give the researchers feedback on the workshop materials and process (data not reported here; see Blades 2013).

Phone interviews were digitally recorded and transcribed. Following transcription, initial codes (high-level themes) were developed by one researcher and then evaluated by other members of the research team for clarity and completeness. The same codes were used for the pre- and postworkshop interviews and discussion group themes. After several initial rounds to refine the coding rules, all interviews and discussion points were coded using NVIVO 10.0 software (QSR International 2012) by one researcher. A subset of interviews and discussion points were subsequently coded by a second researcher to establish reliability (kappa $=0.80 ;$ Krippendorff 2004). Subthemes were subsequently developed under each high-level theme (code) using a peer-debriefing process in which each researcher independently established important and cross-cutting points from the interviewees and the group summarized and corroborated common themes (Appendix 2).

\section{Results}

We interviewed 60 individuals prior to participating in the workshops; 35 of those individuals were also interviewed after the workshop. In all, 77 resource managers participated in the 4 workshops, 61 of whom completed both the pre- and postworkshop online surveys. The responses we received from repeatedly engaging participants through different mediums allowed us to sufficiently understand managers' perceptions and to reach saturation of themes during the interviews and breakout discussions (Bowen 2008). In presenting results below, we integrate excerpts from interviews and workshop discussions chosen to exemplify the general themes we distilled from across the data sources we collected (Bansal and Corley 2012, Poortman and Schildkamp 2012).

\section{Usefulness of climate change science}

The majority of survey participants thought climate change science was useful for their work $(90 \%)$, for future planning efforts $(97 \%)$, or for specific management projects $(80 \%$; Fig. 2). Furthermore, more than $80 \%$ of the land managers surveyed 
agreed or strongly agreed that using climate change science was within their job description or responsibilities (Fig. 2), indicating an awareness of national policies aimed at adapting to and mitigating climate change. When asked in interviews and workshop discussions how climate change science is currently being used, many participants mentioned that it is addressed in environmental impact statements (EISs), environmental assessments (EAs), and forest plans that have been recently revised, along with other disturbance factors, e.g., wildfire, bark beetles, floods. However, these documents often contain only broad, nonspecific language. For example, one hydrologist mentioned that "cursory statements are put into our EISs or EAs, and it's more like checking a box than it is really looking into what ... could be the potential effects [of climate change]."

Fig. 2. Percentage of survey participants that agreed with, felt neutral about, or disagreed with the statements in the pre- and postworkshop interviews regarding the usefulness of climate change science (top panel) and barriers to using the science to adapt or mitigate the impacts of climate change (bottom panel). The "\% Agree" column displays the percentage of participants that strongly agreed $(+3$; black bars), agree $(+2$; grey bars), or slightly agreed $(+1$, white bars) with the listed survey statements. The same is true in the "\% Disagree" column. Neutral (neither agree nor disagree) responses are not displayed; thus, bars may not sum to $100 \%$.

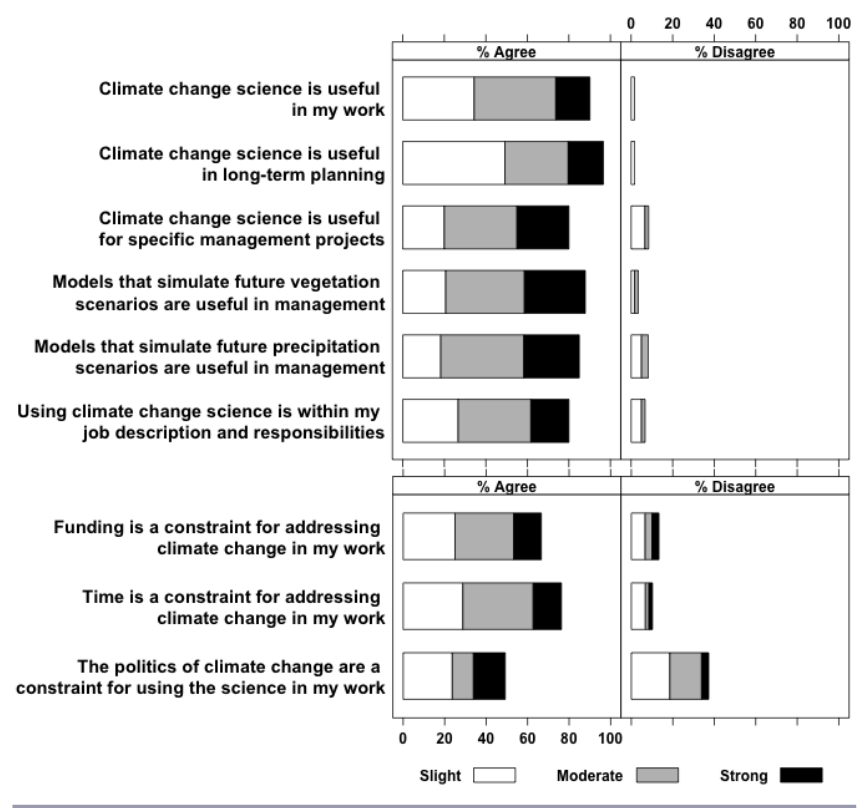

During the workshop discussions, participants emphasized that climate change projections were useful for showing that adaptation may be necessary, but less useful in understanding how to adapt. This uncertainty about the best adaptation strategies meant that many of the resource managers we interviewed were unlikely to change their management practices to accommodate future change. For example, a timber manager from the USFS noted that he was not going to "change the species compositions when I prescribe a plant in a revegetation harvest area." Rather, he emphasized he would use the "stand dynamics [of] what has been there" to influence his "decision on what we're going to [plant in that stand] in the future." Likewise, managers found it difficult to understand how to incorporate climate change science into their planning efforts. For example, one planner noted that many of the USFS's management actions are still based on "our current understanding of climate being relatively static." This planner went on to emphasize that "We're not sure [of] the extent of climate change or what a $3^{\circ} \mathrm{C}$ increase in the global [mean temperature] means to us here locally. That's the problem, we know that there's a change globally, but what does that mean here on our 250,000 acres that we manage in northwest Montana? That has yet to be defined for us at a level we can [base] management decisions on." Like this individual, many other participants pointed out that "project level planning [takes place over] pretty short time periods (5-10 years)" and at the scale of hundreds of acres, requiring "very site-specific analysis," whereas climate change occurs over long periods and specific local impacts are difficult to predict. Thus, the current global and national-scale climate change projections are not very applicable for planning on-the-ground management activities.

Of the three spatial scales of information presented during the workshops (i.e., global, regional, and local), regional and local climate change projections were considered more useful for land management than global projections $\left(\mathrm{F}_{3,234}=11.87, \mathrm{p}<<0.001\right.$; Table 1). However, interviews and workshop discussions revealed a more nuanced interpretation of the usefulness of different scales of information. Discussions during the workshop revealed that participants felt that "local-scale models lacked site-specific data" or that "there was too much variability" at this scale. One silviculturist felt that local-scale models had to consider "so many variables and so many complexities in the natural system" and that modeling those types of processes was "really hard." Workshop participants did comment that, conceptually, the scale of regional projections was useful for thinking about "potential consequences or priorities" and "desired future conditions" across the broader landscape.

Table 1. Mean score for each statement about the usefulness of climate change ( -3 to +3 , strongly disagree to strongly agree) \pm 2 standard errors. An analysis of variance with Tukey's post hoc tests was performed to determine the statistical significance of differences in mean ratings between each type of information. Superscripts that differ indicate values that differ at alpha $=0.05$. $\mathrm{N}$ indicates the number of responses to each prompt.

\begin{tabular}{lcc}
\hline \hline Items & $\mathrm{N}$ & Mean $\pm 2 \mathrm{SE}$ \\
\hline $\begin{array}{l}\text { The global climate change information is } \\
\text { useful for land management (modeling and } \\
\text { emission scenario information). }\end{array}$ & 60 & $1.4 \pm 0.2^{\mathrm{a}}$ \\
$\begin{array}{l}\text { The regional climate and water research is } \\
\text { useful for land management. }\end{array}$ & 61 & $2.2 \pm 0.2^{\mathrm{b}}$ \\
$\begin{array}{l}\text { The regional vegetation and fire research is } \\
\text { useful for land management. }\end{array}$ & 59 & $2.2 \pm 0.2^{\mathrm{b}}$ \\
$\begin{array}{l}\text { The local-scale forest vegetation and climate } \\
\text { simulations are useful for land management. }\end{array}$ & 58 & $1.9 \pm 0.2^{\mathrm{b}}$ \\
\hline
\end{tabular}

Management to address the impacts of climate change

Participants were asked during the interviews and workshops if there were specific actions they felt would be useful for adapting 
to and mitigating the effects of climate change on federally managed public lands in Idaho and Montana. Surveys addressed 10 specific management strategies that could be implemented to adapt to climate change; participants were asked to evaluate the likelihood and effectiveness of each of these strategies (Fig. 3).

Fig. 3. Mean response to 10 survey questions asking participants $(n=61)$ to evaluate the efficacy of different management strategies for adapting to climate change in Idaho and Western Montana. Participants were asked to rate whether they felt they actions listed would be effective (white bars) and the likelihood that their agency would use each action (grey bars) to adapt to the impacts of climate change. Responses were scaled from -3 (very ineffective/unlikely) to +3 (very effective/likely). Management actions that were more likely to be considered effective and likely to be implemented in response to climate change are at the top of the figure. Actions that were perceived to be ineffective and have a low likelihood of implementation are at the bottom of the figure. Error bars indicate \pm 2 standard errors around the mean. HRV stands for Historical Range of Variability and refers to the range of potential conditions (e.g., disturbance, climate) that a particular ecotype may have experienced prior to European settlement and heavy anthropogenic manipulation of the landscape.

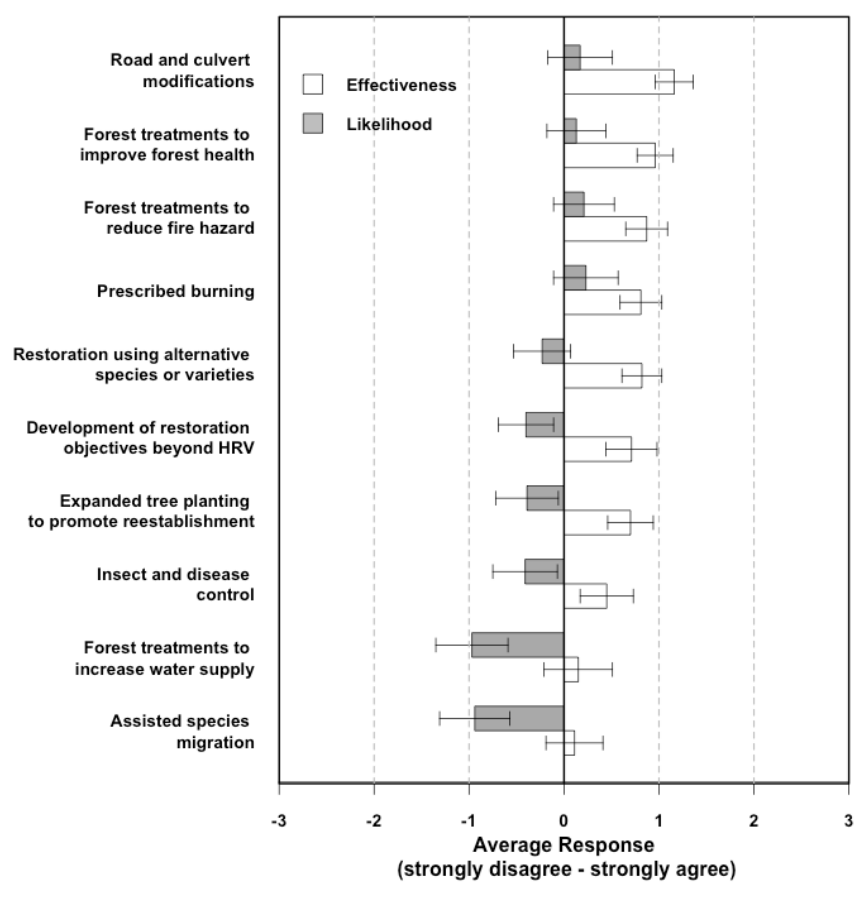

Actions considered most effective were forest treatments to reduce fire hazard and improve forest health (e.g., thinning projects aimed at decreasing tree density or removing hazardous fuels) and infrastructure modification (e.g., replacement of existing roads and culverts to make them less flood prone; Fig. 3). For example, one interview participant noted that "upsizing culverts to prepare for earlier spring [snow] melts, or more precipitation falling as rain during that time period where it might be snow instead" could be effective for adapting to climate change. Participants also felt that infrastructure modifications, forest treatments to improve forest health and reduce fire hazard, and prescribed burning were the management actions that were most likely to be carried out by the USFS or the BLM in response to potential climate change impacts. Restoration using alternative tree species or varieties that might be more resilient to climate change was considered potentially effective by participants, but less likely to be used by their agencies (Fig. 3). For example, one manager commented that "we have not gotten into the mode of assisted migration or changing our species that we're planting because of what we think may happen in the future as the climate changes." Finally, participants felt that actions such as forest thinning to increase water availability (e.g., targeted thinning of conifers encroaching into wet meadows or semiarid shrublands) or the intentional movement of species to areas or habitats predicted to be favorable in the future but currently outside their range (i.e., assisted species migration) were neither likely nor effective (Fig. 3).

Although a few participants mentioned specific adaptation strategies during the interviews and breakout discussions, most participants felt uncertain about potential management actions that could help their agencies adapt to or mitigate climate change. "I think we are challenged to sort out what [to do] about climate change ... we don't really know what we can do ... I think we all realize that we are sort of bystanders to this,"said one participant. Consistent with the surveys, participants who discussed specific management treatments for adapting to climate change in their interviews focused on using familiar techniques such as thinning or prescribed burning.

Nearly half $(46 \%)$ of the interviewees emphasized increasing "resilience" of forests for multiple objectives in their comments about how climate change adaptation might occur. Increasing resilience was also a common theme of group discussions during the workshops. For example, a planner with the BLM mentioned that the agency is "trying to make sure our streams are as resilient as possible [so we do a lot of restoration activities to] remove the stream barriers, fish barriers, things that would warm temperatures..." Another planner mentioned that because climate change is "an uncertainty that we can't necessarily predict and/or manage for," the best management option might be to manage for a diversity of "[tree] age classes and species" to have something that might be "resilient in the future." Resilience has been emphasized in many of the federal climate change policies, and this concept seemed to resonate with resource managers thinking about potential adaptation strategies.

Several participants expressed frustration that the amount of land they could effectively treat would be minimal compared with the potential impacts of climate change. "I'm looking at a map right now ... and I'm [thinking] I could do something on the ground that would cost a bunch of money [and it] would be great, but in the grand scheme of things, it would only be a tiny, tiny piece of ground that I'm actually doing any good on," commented one ecologist. Participants also recognized that the scale of land management being done currently might not be effective in mitigating climate change, i.e., reducing carbon emissions. For example, one forester from a regional USFS office noted that because of the extensive vegetated area his agency manages, "there are carbon storage issues that we could deal with in terms of reducing fire hazard and the large mass of carbon released from wildfire events." However, this forester went on to comment that 
social barriers (e.g., litigation by environmental interest groups) limit the amount of area they can effectively treat. Because of these limitations, resource managers felt that they would instead be forced to adapt their management to deal with the impacts of climate change after the fact. "Our projects aren't going to affect [climate change] but we will be affected by it, so what is our management going to do to respond?" one participant asked. "Adaptation is probably going to be the key," noted another.

Furthermore, although previous policy has guided land management to consider historical reference conditions as a baseline for restoration, a few of the interviewees recognized that, in light of climate change, restoring to those conditions might no longer be a viable goal. For example, one silviculturist stated that "the thinking [in the USFS] ... has been that if we restore things to within the historical range of variability, we somehow increase resistance and resilience to change. Now, we have to construct what could be the [future] ranges that will function with climate change." Seventy percent of participants surveyed prior to the workshop agreed that their agencies might be willing to explore alternative management solutions beyond restoring to reference conditions. Nevertheless, the totality of the survey, interview, and workshop data suggests that managers don't know what those solutions should be.

\section{Barriers to use and implementation of climate change science} Our survey included three potential barriers based on the literature: time, funding, and politics (Fig. 2). Time was mentioned frequently in the workshop group discussions; representative comments included "there is not enough time to learn new tools" and "there are so many other priorities, [that] climate change is just one more thing [that requires] time." Participants also commented that part of the difficulty in using climate change science was keeping up with the wealth of information that is continuously being published, when there is little time to "know all the latest, greatest science that's out there, and to have it readily available at your fingertips." Being able to readily access information in a concise format would reduce some of the perceived barriers participants had with using the science. Participants also elaborated on the issue of funding for climate change adaptation projects. For example, on regional planner emphasized that without "extra resources in terms of capacity or funding, how are [resource managers] supposed to do [anything about climate change]?"

External politics and litigation by public interest groups also appeared in the interviews as a major barrier that participants perceived to limit their ability to manage for the impacts of climate change in the future. Managers noted that much of their energy was devoted to dealing with issues that were of current concern to the public, leaving little time to focus on new issues like climate change. "You can [only] do so many projects and so you don't spend a lot of time on things that you're not being challenged on. The climate change [issue] seems to be an emerging issue that we're not actually pursued on yet. The things that you get pursued on are the ones you start paying more attention to," one forest planner noted in an interview. Another planner commented that even though "the Washington office [of the USFS says] we're [going to do] more accelerated restoration, and massive thinning [to mitigate for climate change], the reality is we get appealed and then we get litigated." This planner went on to say that managers "can't do anything on the ground without getting through the [environmental] issues, [which is] really such a sociopolitical piece of [management]."

Beyond the items included in the survey, participants discussed several other institutional barriers in workshop discussions and interviews related to using climate change science for management decisions. For example, the size of the agencies and the associated bureaucracy mean that changes occur slowly and new ideas and management strategies are unlikely to catch on quickly. Comments from USFS employees such as, "the Forest Service is a big machine ... with a lot of ingrained ideas of what we do" or "because of the bureaucracy, things happen very slowly" were widespread throughout the group discussions and interviews. Many participants commented that in recent decades agencies have often operated reactively, dealing with issues after they become problems rather than anticipating situations and proactively addressing them. For example, one hydrologist remarked, "It's not like we are waiting for [climate change] to come in. It's been here for a couple of decades. We haven't changed things, really. We're talking about how we're going to do this, and we should be talking about how we should have done this." Although slow, some participants were optimistic that changes in ingrained management practices would eventually occur. One participant gave this example: "To change livestock grazing, for example, [might be] kind of a hard thing to do, but it seems like when people aren't meeting permit stipulations that things will have to change. It might take a while before they realize actually that this is not just a weird year, this is a weird decade, [and] we are still not meeting targets year after year."

Additionally, several participants noted a lack of organizational capacity to address climate change; that is, people are not trained and/or educated about climate change and there is no time or funding to support this effort, and even if managers have the training, the expertise, or the inclination, the support and direction from higher levels may be lacking. One forest planner acknowledged that "[climate change] is a stated policy of the Forest Service, there's no question about that. But that doesn't mean every district ranger, every forest supervisor, believes in it. That then gets reflected in their program of work and what they emphasize." Another manager relayed a similar view: "We have the people, we have the experience and expertise and technical savvy to get this done. We need the support to be able to do it." Participants emphasized that upper-level decision makers (e.g., district rangers and forest supervisors) had the final say on what projects get done on national forests and rangelands; therefore, it was "up to [the decision makers] to decide whether they want to take a risk or not [to do something about climate change]." Poor organizational support meant that these managers had little motivation to incorporate climate change into their planning efforts unless they were getting specific direction from these line officers.

\section{Discussion}

Many of the federal resource managers we interacted with from Idaho and western Montana USFS and BLM offices think that climate change science could be useful for the work they do, demonstrating that they consider climate change to be a salient issue with the potential to impact the resources they manage. Except for brief and oblique mentions of "climate change 
resilience" in land-use plans, few of the public land managers we surveyed indicated that they were actively using climate change science in their work. This result is likely to vary depending on the specific district or forest that individuals work on; for example, other national forests and BLM districts (e.g., the OkanoganWenatchee, Colville, and Olympic National Forests in the nearby state of Washington) have been proactive about incorporating climate change science into forest-wide strategic plans (West et al. 2009, Halofsky et al. 2011) and are likely to have much more comprehensive guidelines in place for addressing the impacts of climate change in their planning efforts. However, our findings were consistent with results from interviews with natural resource managers in the southern Rocky Mountains about the usefulness of climate change science (Ellenwood et al. 2012), suggesting that the integration of climate change science into management planning may still be evolving.

The usability of climate change science is influenced by whether an appropriate scale of information exists and if the science is informative within the specific end-user decision-making context (Dilling and Lemos 2011). Our results indicate that science at temporal and spatial scales that matched the scale of project planning was an important consideration when participants were evaluating the usefulness of climate change science. In our workshops, local- to regional-scale information that emphasized risk management and long-term planning (e.g., watershed projections of changing precipitation phases; Klos et al. 2014), monthly stream flow, and flood risk (Hamlet et al. 2010), were considered especially useful by resource managers. Downscaled climate change projections that focus on subregional scales and project impacts over shorter time frames are likely to be much more applicable to managers' goals (Letson et al. 2001, Rayner et al. 2005, Dilling and Lemos 2011, Archie et al. 2014). Where these resources can be made available through freely available outlets such as websites or personal blogs, they are more likely to be successfully accessed and applied to project planning (Archie et al. 2014).

Science that is "coproduced" by managers and scientists and tailored for specific resources or targeted to potential actions has also been shown to be effective in overcoming informational barriers (Lemos and Morehouse 2005, Joyce et al. 2009, Dilling and Lemos 2011, Kocher et al. 2012, Littell et al. 2012, Moss et al. 2013). This approach has been used effectively in wildland fire (Kocher et al. 2012) and water resources management (White et al. 2008, Wilder et al. 2010). For example, hydrologic studies indicating the quantity or timing of available water sources can dictate how water is allocated for agriculture, development, or other uses (e.g., White et al. 2008). For wildland fire management, forecasts informed by current science are used to allocate appropriate resources for the coming fire season. Science that focuses on management-relevant objectives and needs, such as information on fuels and long-term weather forecasts, is used to make decisions in the face of uncertain potential outcomes (Lemos and Morehouse 2005). Organizational structures that help bridge the boundary between science and management (e.g., boundary organizations) are likely to be key in maintaining an environment where scientists and managers can continually discuss relevant needs (e.g., White et al. 2008). In some cases, these structures already exist in the U.S. northern Rocky Mountains, where USFS-funded Collaborative Forest Landscape Restoration
Projects encourage collaborative, science-based ecological restoration. Although the goal of these organizations is not climate change adaptation per se, as these organizations become institutionalized, they could serve as effective vehicles for knowledge production and sharing across administrative boundaries (Gaines et al. 2012). Approaches such as single or multiday workshops or focus groups may also be effective for helping managers develop general adaptation strategies to deal with climate change (Littell et al. 2012, Blades 2013).

Although climate information at management-relevant scales is starting to become available in the research community, access to that information may still be an issue for managers looking to use it (e.g., White et al. 2008). Where information is accessible, it is often in a format that is difficult for managers to digest and apply. Several participants stated that they had neither the time nor the expertise to sort through the climate change science that is currently available. National forests have attempted to bridge this gap by creating regional and forest-specific climate change coordinator positions (Tribbia and Moser 2008). These individuals are responsible for collaborating with scientists to create, compile, and disperse regional climate change science relevant for each forest. However, the degree to which this task is effectively carried out often depends on the individuals, their motivation, and their other job responsibilities. This variability was evident in our study; participants in one workshop location were well informed about climate change projections and impacts because of effective communication between their regional climate change coordinator and personnel at the forest and district levels. However, participants in other workshops were not nearly so well informed. Prior studies have emphasized the importance of colleagues as information sources for federal resource managers (Tkacz et al. 2010); thus, well-informed climate change coordinators and line officers may play an essential role in getting climate change science incorporated into day-to-day land management activities (Archie et al. 2014).

In addition to a lack of management-relevant information, lack of specific agency guidance, resources such as time and funding, and public support were the most frequently mentioned constraints when our study participants were asked to elaborate on barriers that prevented their use of climate change science. Although we did not separate responses from BLM or USFS participants, prior studies indicate that these agencies may face similar challenges. Specifically, lack of information at relevant scales and budget constraints were cited by both BLM and USFS employees as perceived barriers to adaptation planning (Archie et al. 2012). Furthermore, lack of agency guidance or direction is cited as one of the biggest limitations in prioritizing climate change in land management decisions (GAO 2007). Specific agency direction was a more significant barrier for individuals from the BLM than the USFS (Archie et al. 2012), although we heard from USFS and BLM participants alike that the necessary support and guidance from line officers and decision makers at the planning-unit or forest level was currently lacking. Time, funding, and internal and external politics are also barriers to using scientific data and information in land-use planning and management (e.g., Dilling and Lemos 2011, Mukheibir et al. 2013). The managers participating in our study felt their agencies were reluctant to commit time and money to projects when there was uncertainty about the magnitude, timing, or probability of a 
climate change impact. Finally, several of our study participants felt that climate change was not yet a high-profile public issue and was therefore unlikely to be prioritized within current management. Management priorities are often shaped by public opinion (Archie et al. 2012, Ellenwood et al. 2012), especially because public comment is required by the National Environmental Policy Act for any management activity that has potential ecological impacts. Competing priorities may limit how much time resource managers feel they can allocate to training, education, or synthesis of climate change science (GAO 2007, Jantarasami et al. 2010), while also impacting the likelihood that climate change adaptation projects will be funded, implemented, and publically supported.

Although recent federal policies guide managers to consider the implications of climate change at all levels of land management planning, most managers we interviewed are not yet thinking about or addressing climate change directly with specific projects. Of the particular management actions addressed in our surveys, participants generally felt that existing management strategies (e.g., thinning and prescribed burning) would be the most effective and likely to be implemented in response to climate change (Fig. 1). Management actions that are already widely implemented on public lands to meet other objectives are more likely to be supported by decision makers and have relatively little risk of eliciting negative public opinion (GAO 2007), which can be the key to success in a land management agency that must respond to both public input and litigation. For example, former lawsuits that resulted in legal decisions regarding certain management actions may set a precedent that allows managers to know what existing management actions they can take without being formally challenged. Additionally, using existing policies where applicable would allow agencies to meet multiple goals without having to necessarily anticipate the future extent and timing of climate-related impacts (Joyce et al. 2009). The Healthy Forest Restoration Act of 2003 (PL 108-148), for example, allows increased forest thinning and prescribed fire to reduce hazardous fuels and wildfire. This policy could be used as support for ongoing and accelerated restoration and fuels treatments that increase forest resilience to disturbance-related impacts of climate change.

Novel adaptation strategies such as assisted species migration, expanding the genetic stock for revegetation, or managing for future insect and disease outbreaks (e.g., Joyce et al. 2008), on the other hand, were rarely discussed in interviews or workshop discussions, and surveys indicated that most resource managers felt these strategies were unlikely to be implemented by the USFS or the BLM. Even though these adaptation strategies might be effective for dealing with climate change, they require anticipation of the timing and extent of future shifts in, for example, species composition or the frequency of extreme events (see Joyce et al. 2009). Many managers recognize the nonlinear nature of ecological responses and the stochasticity of disturbance events, which may lead to their reluctance to adopt strategies that rely on future climate and species distribution projections (Joyce et al. 2008). Likewise, extensive monitoring, changes to existing policies and regulations, or adoption of new policies may be required to make novel adaptation strategies a more feasible option (Joyce et al. 2008). For example, although management activities such as assisted migration have been effective in a few trials aimed at eliminating the risk of species extinctions (Joyce et al. 2008) or expanding ranges for commercially valuable timber species (e.g., Willis et al. 2009), there are still tremendous political and ethical ramifications of planting species outside their naturalized range (e.g., Pedlar et al. 2011), and there is little policy guidance about when and where this adaptation strategy is appropriate (McLachlan et al. 2007, Schwartz et al. 2012).

Uncertainty about the potential impacts of climate change led many of our participants to focus on general goals or outcomes rather than specific management strategies such as managing forests and rangelands to be more resilient to future climatic changes. Resilient ecosystems are those that have a greater capacity to gradually respond to climate perturbations or recover more rapidly after disturbance (McLachlan et al. 2007). Although management over the past several decades has often focused on restoring resilience by returning the landscape to historical reference conditions, climate change may necessitate a different approach (Millar et al. 2007, Hobbs et al. 2014). Therefore, guidance is needed to define what ecosystem resilience may look like with potential future changes in climate (West et al. 2009). Basing management decisions on unknown future conditions makes decisions challenging, but proactive adaptive management approaches such as increasing structural and compositional diversity of existing ecosystems, improving connectivity of landscapes for species' migration, and intensive monitoring and treatment after active management are some solutions that have been suggested to allow resource managers flexibility in response to climate change (West et al. 2009). These strategies don't require local-scale or species-specific projections to implement and can be informed by existing ecological knowledge. However, these solutions may only be viable so long as major ecosystem transitions do not occur. Over the long-term, management approaches may need to shift with shifts in ecosystems and resources (Millar et al. 2007, Joyce et al. 2009, West et al. 2009).

\section{Conclusion}

Although the science on potential climate change impacts continues to grow and be refined, the types of climate change research that resource managers in the USFS and the BLM perceive to be available and accessible are not currently effective for creating management prescriptions. However, rather than uniformly increasing the supply of climate science, federal land managers need a process in which they can repeatedly and collaboratively interact with scientists in production and compilation of climate change science that is usable and applicable (Dilling and Lemos 2011). These collaborative efforts could alleviate perceived barriers associated with lack of personnel and resources to develop the information independently (Archie et al. 2014). Federal resource managers desire scale-relevant research focused at subregional scales (Archie et al. 2014). Projections that focus on impacts that have direct applicability to management priorities, such as projections about vulnerabilities to fire, flooding, or habitat loss, may be perceived as more useful. Because peer-reviewed journals are not easily accessible or readily used by federal land managers (Archie et al. 2014), having information available on regularly updated websites or blogs could be an important way to ensure its accessibility. Additionally, federal land managers could benefit from workshops, webinars, or trainings that serve as boundary 
objects for synthesizing relevant information and aim to bridge the research-management gap. The framework for these boundary organizations may already exist in Collaborative Forest Landscape Restoration Programs, Landscape Conservation Cooperatives, and other efforts in place nationally and across the U.S. northern Rocky Mountain region. These organizations could play an active role in disseminating climate change science and serve as fertile ground for future research about the effectiveness of boundary objects and organizations.

Having appropriate information is only one part of the challenge of effectively managing for the impacts of climate change. Knowing how to apply that information and having the support and resources to take action are also essential. On public lands managed by the USFS and the BLM in the U.S. northern Rocky Mountains, there is a disconnect between mandates at the national level and actions that are being taken at the district or field office level. Although national policies for climate change adaptation and mitigation are in place, resource managers still lack the specific guidance and support from decision makers in upper management that would allow them to start managing for climate change impacts. Although there is significant uncertainty associated with managing for climate change impacts, low-risk options such as more widely applying current techniques may be an easy and effective way to begin to implement climate change adaptation measures on the ground (Joyce et al. 2009). These options can be informed by existing regional-scale climate change projections that focus on predictions of potential risks, e.g., increased frequency of wildfire, flooding. In the short-term, focusing on where existing treatments can accomplish multiple goals could reduce costs while stretching limited resources. Adapting existing policies to facilitate climate change adaptation may also allow management flexibility and rapid response measures (Joyce et al. 2009). Collaborative efforts between public, private, and nonprofit organizations can increase the suite of viable adaptation options for resource managers by heightening public support and providing guidance on managing more extensive landscapes. Finally, over longer time scales, it will be important to invest in additional research on and monitoring of management strategies that are considered potentially effective but are currently not widely implemented because this may increase the probability of their future adoption by agencies.

Responses to this article can be read online at: http://www.ecologyandsociety.org/issues/responses. $\mathrm{php} / 7522$

\section{Acknowledgments:}

We gratefully acknowledge all of the public land managers and constituents who participated in several rounds of interviews, surveys, and our one-day workshops. We also thank the numerous volunteers on whom our workshop, survey, and interview materials were pretested, including Theresa Jain, Nicholas Crookston, and Jarred Saralecos. Insights and assistance with the development of the workshop materials and climate projections were provided by Jim Morrison and Nicholas Crookston from the USFS, John Abatzoglou and Philip Higuera from the University of Idaho, and
Jeremy Littell from the USGS and the University of Washington Climate Impacts Group. Interviews were coded by Ali Bean. Chad Kooistra, Melissa Clark, and the University of Montana conflict resolution group facilitated discussions during the workshops. Philip Higuera and three anonymous reviewers provided helpful comments that greatly improved the clarity of this manuscript. Funding for this project was provided by NSF-IGERT (DGE-0903479) fellowships to KBK, JJB, PZK, and WTT, and a Joint Fire Science Program Graduate Research Innovation award (JFSP 11-3-1-33) to JJB.

\section{LITERATURE CITED}

Archie, K. M. 2014. Mountain communities and climate change adaptation: barriers to planning and hurdles to implementation in the Southern Rocky Mountain Region of North America. Mitigation and Adaptation Strategies for Global Change 19 (5):569-587. http://dx.doi.org/10.1007/s11027-013-9449-Z

Archie, K. M., L. Dilling, J. B. Milford, and F. C. Pampel. 2012. Climate change and western public lands: a survey of U.S. federal land managers on the status of adaptation efforts. Ecology and Society 17(4): 20. http://dx.doi.org/10.5751/ES-05187-170420

Archie, K. M., L. Dilling, J. B. Milford, and F. C. Pampel. 2014. Unpacking the 'information barrier': comparing perspectives on information as a barrier to climate change adaptation in the interior mountain West. Journal of Environmental Management 133:397-410. http://dx.doi.org/10.1016/j.jenvman.2013.12.015

Bansal, P., and K. Corley. 2012. Publishing in AMJ-part 7: what's different about qualitative research? Academy of Management Journal 55(3):509-513. http://dx.doi.org/10.5465/ amj.2012.4003

Blades, J. 2013. Bridging natural resource communication boundaries: public perceptions of smoke from wildland fires and forest managers' perspectives of climate change science. Dissertation. University of Idaho, Moscow, Idaho, USA.

Bowen, G. A. 2008. Naturalistic inquiry and the saturation concept: a research note. Qualitative Research 8(1):137-152. http://dx.doi.org/10.1177/1468794107085301

Caudle, D., J. DiBenedetto, M. Karl, K. Sanchez, and C. Talbot. 2013. Interagency ecological site handbook for rangelands. Bureau of Land Management, Forest Service, and Natural Resources Conservation Service. U.S. Department of Agriculture, Washington, D.C., USA. [online] URL: http://directives.sc.egov. usda.gov/OpenNonWebContent.aspx?content=33943.wba

Cruce, T., and H. Holsinger. 2010. Climate change adaptation: what federal agencies are doing. Pew Center on Global Climate Change, Arlington, Virginia, USA. [online] URL: http://www. c2es.org/docUploads/FederalGovernmentLeadershiponAdaptation Nov2010.pdf

Dillard, D., C. Rose, S. Conard, D. MacCleery, L. Ford, K. Conant, A. Cundiff, and J. Trapani. 2008. Forest Service strategic framework for responding to climate change. U.S. Department of Agriculture, Forest Service, Washington, D.C., USA. [online] URL: http://www.fs.fed.us/climatechange/documents/strategicframework-climate-change-1-0.pdf 
Dilling, L., and M. C. Lemos. 2011. Creating usable science: opportunities and constraints for climate knowledge use and their implications for science policy. Global Environmental Change 21 (2):680-689. http://dx.doi.org/10.1016/j.gloenvcha.2010.11.006

Ellenwood, M. S., L. Dilling, and J. B. Milford. 2012. Managing United States public lands in response to climate change: a view from the ground up. Environmental Management 49(5):954-967. http://dx.doi.org/10.1007/s00267-012-9829-2

Gaines, W. L., D. W. Peterson, C. A. Thomas, and R. J. Harrod. 2012. Adaptations to climate change: Colville and OkanoganWenatchee National Forests. General Technical Report PNWGTR-862. U.S. Department of Agriculture, Forest Service, Pacific Northwest Research Station, Portland, Oregon, USA. [online] URL: http://www.fs.fed.us/pnw/pubs/pnw gtr862.pdf

Government Accountability Office(GAO). 2007. Climate change: agencies should develop guidance for addressing the effects on federal land and water resources. GAO-07-863. Government Accountability Office, Washington, D.C., USA. [online] http:// www.gao.gov/products/GAO-07-863

Gorte, R. W., C. H. Vincent, L. A. Hanson, and M. R. Rosenblum. 2012. Federal land ownership: overview and data. Congressional Research Service. 7-5700: R42346. Congressional Research Service, Washington, D.C., USA. [online] URL: http://www.fas. org/sgp/crs/misc/R42346.pdf

Halofsky, J. E., D. L. Peterson, K. A. O’Halloran, and C. Hawkins Hoffman, editors. 2011. Adapting to climate change at Olympic National Forest and Olympic National Park. General Technical Report PNW-GTR-844. U.S. Department of Agriculture, Forest Service, Pacific Northwest Research Station, Portland, Oregon, USA. [online] http://www.fs.fed.us/pnw/pubs/pnw gtr844.pdf

Hamlet, A. F., P. Carrasco, J. Deems, M. M. Elsner, T. Kamstra, C. Lee, S. Y. Lee, G. Mauger, E. P. Salathe, I. Tohver, and L. W. Binder. 2010. Final project report for the Columbia Basin climate change scenarios project. Climate Impacts Group, University of Washington, Seattle, Washington, USA. [online] URL: http:// warm.atmos.washington.edu/2860/report/.

Hobbs, R. J., E. Higgs, C. M. Hall, P. Bridgewater, F. S. Chapin, III, E. C. Ellis, J. J. Ewel, L. M. Hallett, J. Harris, K. B. Hulvey, S. T. Jackson, P. L. Kennedy, C. Kueffer, L. Lach, T. C. Lantz, A. E. Lugo, J. Mascaro, S. D. Murphy, C. R. Nelson, M. P. Perring, D. M. Richardson, T. R. Seastedt, R. J. Standish, B. M. Starzomski, K. N. Suding, P. M. Tognetti, L. Yakob, and L. Yung. 2014. Managing the whole landscape: historical, hybrid, and novel ecosystems. Frontiers in Ecology and the Environment 12 (10):557-564. http://dx.doi.org/10.1890/130300

Jantarasami, L. C., J. J. Lawler, and C. W. Thomas. 2010. Institutional barriers to climate change adaptation in U.S. national parks and forests. Ecology and Society 15(4): 33. [online] URL: http://www.ecologyandsociety.org/vol15/iss4/art33/

Joyce, L. A., G. M. Blate, J. S. Littell, S. G. McNulty, C. I. Miller, S. C. Moser, R. P. Nelson, K. O. Halloran, and D. L. Peterson. 2008. National forests. Pages 3-1-3-127 in S. H. Julius and J. M. West, editors. Preliminary review of adaptation options for climatesensitive ecosystems and resources. Report by the U.S. Climate Change Science Program and the Subcommittee On Global
Change Research. United States Environmental Protection Agency, Washington, D.C., USA. [online] URL: http://ofmpub. epa.gov/eims/eimscomm.getfile?p download id $=474235$

Joyce, L. A., G. M. Blate, S. G. McNulty, C. I. Millar, S. Moser, R. P. Neilson, and D. L. Peterson. 2009. Managing for multiple resources under climate change: national forests. Environmental Management 44(6):1022-1032. http://dx.doi.org/10.1007/ $\underline{\mathrm{s} 00267-009-9324-6}$

Keane, R. E., P. F. Hessburg, P. B. Landres, and F. J. Swanson. 2009. The use of historical range and variability (HRV) in landscape management. Forest Ecology and Management 258 (7):1025-1037. http://dx.doi.org/10.1016/j.foreco.2009.05.035

Klos, P. Z., T. E. Link, and J. T. Abatzoglou. 2014. Extent of the rain-snow transition zone in the western U.S. under historic and projected climate. Geophysical Research Letters 41(13):4560-4568. http://dx.doi.org/10.1002/2014GL060500

Kocher, S. D., E. Toman, S. F. Trainor, V. Wright, J. S. Briggs, C. P. Goebel, E. M. MontBlanc, A. Oxarart, D. L. Pepin, T. A. Steelman, A. Thode, and T. A. Waldrop. 2012. How can we span the boundaries between wildland fire science and management in the United States? Journal of Forestry 110(8):421-428. http://dx. doi.org/10.5849/jof.11-085

Krippendorff, K. 2004. Reliability in content analysis: some common misconceptions and recommendations. Human Communication Research 30(3):411-433. http://dx.doi.org/10.1111/ j.1468-2958.2004.tb00738.x

Lachapelle, P. R., S. F. McCool, and M. E. Patterson. 2003. Barriers to effective natural resource planning in a "messy" world. Society \& Natural Resources 16(6):473-490. http://dx.doi. org/10.1080/08941920309151

Lemos, M. C., and B. J. Morehouse. 2005. The co-production of science and policy in integrated climate assessments. Global Environmental Change 15(1):57-68. http://dx.doi.org/10.1016/j. gloenvcha.2004.09.004

Letson, D., I. Llovet, G. Podestá, F. Royce, V. Brescia, D. Lema, and G. Parellada. 2001. User perspectives of climate forecasts: crop producers in Pergamino, Argentina. Climate Research 19 (1):57-67. http://dx.doi.org/10.3354/cr019057

Littell, J. S., D. L. Peterson, C. I. Millar, and K. A. O'Halloran. 2012. U.S. National Forests adapt to climate change through science-management partnerships. Climatic Change 110 (1-2):269-296. http://dx.doi.org/10.1007/s10584-011-0066-0

McLachlan, J. S., J. J. Hellmann, and M. W. Schwartz. 2007. A framework for debate of assisted migration in an era of climate change. Conservation Biology 21(2):297-302. http://dx.doi. org/10.1111/j.1523-1739.2007.00676.x

Millar, C. I., N. L. Stephenson, and S. L. Stephens. 2007. Climate change and forests of the future: managing in the face of uncertainty. Ecological Applications 17(8):2145-2151. http://dx. doi.org/10.1890/06-1715.1

Moss, R. H., G. A. Meehl, M. C. Lemos, J. B. Smith, J. R. Arnold, J. C. Arnott, D. Behar, G. P. Brasseur, S. B. Broomell, A. J. Busalacchi, S. Dessai, K. L. Ebi, J. A. Edmonds, J. Furlow, L. Goddard, H. C. Hartmann, J. W. Hurrell, J. W. Katzenberger, D. 
M. Liverman, P. W. Mote, S. C. Moser, A. Kumar, R. S. Pulwarty, E. A. Seyller, B. L. Turner, W. M. Washington, and T. J. Wilbanks. 2013. Hell and high water: practice-relevant adaptation science. Science 342(6159):696-698. http://dx.doi.org/10.1126/science.1239569

Mukheibir, P., N. Kuruppu, A. Gero, and J. Herriman. 2013. Overcoming cross-scale challenges to climate change adaptation for local government: a focus on Australia. Climatic Change 121 (2):271-283. http://dx.doi.org/10.1007/s10584-013-0880-7

Pederson, G. T., S. T. Gray, D. B. Fagre, and L. J. Graumlich. 2006. Long-duration drought variability and impacts on ecosystem services: a case study from Glacier National Park, Montana. Earth Interactions 10(1):1-28. http://dx.doi.org/10.1175/ EI153.1

Pedlar, J., D. McKenney, J. Beaulieu, S. Colombo, J. McLachlan, and G. O'Neill. 2011. The implementation of assisted migration in Canadian forests. Forestry Chronicle 87(6):766-777. http://dx. doi.org/10.5558/tfc2011-093

Poortman, C. L., and K. Schildkamp. 2012. Alternative quality standards in qualitative research? Quality \& Quantity 46 (6):1727-1751. http://dx.doi.org/10.1007/s11135-011-9555-5

President of the United States. 2009. Executive Order 13514. Federal leadership in environmental, energy, and economic performance. Federal Register 74(194):52117-52172. [online] URL: http://www.gpo.gov/fdsys/pkg/FR-2009-10-08/pdf/E9-24518. pdf

President of the United States. 2013. Executive Order 13653. Preparing the United States for the impacts of climate change. Federal Register 78(215):66819-66824. [online] URL: http://www. gpo.gov/fdsys/pkg/FR-2013-11-06/pdf/2013-26785.pdf

QSR International. 2012. NVivo Qualitative Data Analysis Software, Version 10. QSR International, Melbourne, Australia.

Rayner, S., D. Lach, and H. Ingram. 2005. Weather forecasts are for wimps: why water resource managers do not use climate forecasts. Climatic Change 69(2-3):197-227. http://dx.doi. org/10.1007/s10584-005-3148-Z

Schwartz, M. W., J. J. Hellmann, J. M. McLachlan, D. F. Sax, J. O. Borevitz, J. Brennan, A. E. Camacho, G. Ceballos, J. R. Clark, H. Doremus, R. Early, J. R. Etterson, D. Fielder, J. L. Gill, P. Gonzalez, N. Green, L. Hannah, D. W. Jamieson, D. Javeline, B. A. Minteer, J. Odenbaugh, S. Polasky, D. M. Richardson, T. L. Root, H. D. Safford, O. Sala, S. H. Schneider, A. R. Thompson, J. W. Williams, M. Vellend, P. Vitt, and S. Zellmer. 2012. Managed relocation: integrating the scientific, regulatory, and ethical challenges. BioScience 62(8):732-743. http://dx.doi.org/10.1525/ bio.2012.62.8.6

SPSS. 2010. Statistical package for the social sciences, Version 13.0. SPSS, Chicago, Illinois, USA.

Tkacz, B., H. Brown, A. Daniels, A. Acheson, D. Cleland, F. Fay, R. Johnson, G. Kujawa, B. Roper, and L. Stritch. 2010. National roadmap for responding to climate change. FS-957b. U.S. Department of Agriculture, Forest Service, Washington, D.C., USA. [online] URL: http://www.fs.fed.us/climatechange/pdf/ roadmap.pdf
Tribbia, J., and S. C. Moser. 2008. More than information: what coastal managers need to plan for climate change. Environmental Science \& Policy 11(4):315-328. http://dx.doi.org/10.1016/j. envsci.2008.01.003

West, J. M., S. H. Julius, P. Kareiva, C. Enquist, J. J. Lawler, B. Petersen, A. E. Johnson, and M. R. Shaw. 2009. U.S. natural resources and climate change: concepts and approaches for management adaptation. Environmental Management 44 (6):1001-1021. http://dx.doi.org/10.1007/s00267-009-9345-1

White, D. D., E. A. Corley, and M. S. White. 2008. Water managers' perceptions of the science-policy interface in Phoenix, Arizona: implications for an emerging boundary organization. Society \& Natural Resources 21(3):230-243. http://dx.doi. org/10.1080/08941920701329678

Wilder, M., C. A. Scott, N. P. Pablos, R. G. Varady, G. M. Garfin, and J. McEvoy. 2010. Adapting across boundaries: climate change, social learning, and resilience in the US-Mexico border region. Annals of the Association of American Geographers 100 (4):917-928. http://dx.doi.org/10.1080/00045608.2010.500235

Willis, S. G., J. K. Hill, C. D. Thomas, D. B. Roy, R. Fox, D. S. Blakeley, and B. Huntley. 2009. Assisted colonization in a changing climate: a test study using two U.K. butterflies. Conservation Letters 2(1):46-52. http://dx.doi.org/10.1111/ j.1755-263X.2008.00043.X

Wright, V. 2010. Influences to the success of fire science delivery: perspectives of potential firelfuels science users. Final Report to the Joint Fire Sciences Program. JFSP Protect \#04-4-2-01. Joint Fire Sciences Program, Boise, Idaho, USA. [online] URL: $\underline{\text { http:// }}$ www.firescience.gov/projects/04-4-2-01/project/04-4-2-01_vw_jfsp final report.pdf 
Appendix 1. Interview questions asked to participants before and after the workshops. All questions were open-ended, allowing for a range of responses from participants.

\section{Pre- workshop interview questions}

1. Do you use climate change science in the work you do? How?

2. Other than personal use, is your organization currently using science about climate change impacts? How?

3. Tell me what you think about the usefulness of climate change science in the work you do. What makes it useful or impedes its usefulness?

a. Are there organizational barriers that impede usefulness?

4. Are you aware of forest management actions that could reduce climate change impacts? (e.g., Specific on-the-ground actions)

5. Are any of these actions being done now? Why or why not?

6. How confident do you feel in the ability of your organization/agency to take actions to reduce the potential impacts of climate change? Will they do it?

7. Do have anything else you would like to add about what we have discussed today?

\section{Post-workshop interview questions}

1. How useful is the climate change science and tools we presented at the workshop for the work you do? What makes it useful or impedes its usefulness?

2. Based on the information presented at the workshops, how confident do you feel in the ability of your organization/agency to take actions to reduce the potential impacts of climate change? Will they do it? 
Appendix 2. Interview questions, common response themes, and example participant quotations for each high level code.

\section{USEFULNESS}

\section{Example interview questions}

- Do you use climate change science in the work that you do? How?

- What makes [climate change science] useful or impedes its usefulness [in the work you do]?

\section{Common response themes}

- Cursory language about climate change science is used in regional land-use planning documents, environmental impact statements (EISs), and environmental assessments (EAs)

- Scale is an issue; climate change science is not local or site-specific enough to be useful

\section{Example participant quotes}

- "Generally, we say the link between greenhouse gas emissions and climate change should be discussed, the capacity of a project to adapt to projected climate change effects disclosed, if there are going to be significant emissions, the cumulative emissions, recognizing that it's a global cumulative effect issue."

- "The projects that I work on [require] very site-specific analysis. Trying to use the current [climate change] research, which is global in many cases or national, and trying to bring that down to the site-specific level and use it meaningfully in project analysis... there just isn't any way right now."

\section{RESPONSE EFFICACY}

\section{Example interview questions}

- Are you aware of forest management actions that could reduce climate change impacts?

\section{Common response themes}

- Familiar management actions that meet multiple objectives are more likely to be used to adapt to climate change

- Increasing "resilience" will increase capacity of ecosystems to adapt to climate change

- Management focuses on restoring ecosystems to reference conditions using the historic range of variability (HRV) concept; restored ecosystems will be better able to adapt

\section{Example participant quotes}

- "Management activities that reduce [tree] density [and] improve resilience to fire and drought are going to be consistent with management activities [to reduce climate change impacts]."

- "[The best management option is to] have a diversity of age classes and species represented on the landscape... [so] there's something out there that will be resilient in the future."

- "The thinking [in the USFS]...has been that if we restore things to within the 
historical range of variability, we somehow increase resistance and resilience to change."

\section{COLLECTIVE EFFICACY}

Example interview questions

- How confident do you feel in the ability of your organization or agency to take actions to reduce the potential impacts of climate change? Will they do it?

\section{Common response themes}

- Institutional barriers mean that managers are unable to treat enough land to effectively adapt to climate change

\section{Example participant quotes}

- "There are social barriers that... limit our ability to manage down to such a small fraction of [the] overall landscape that I don't think we're going to [get] to a point that we can [have] any measurable or significant effect."

\section{BARRIERS}

\section{Example interview questions}

- Are there organizational barriers that impede [the] usefulness [of climate change science]?

\section{Common response themes}

- Time, funding, and politics (esp. concerning litigation and public perceptions)

- Informational barriers such as accessibility and applicability limit usefulness

- A lack of organizational capacity, esp. training and/or education about climate change and potential management actions to respond to it

- Inconsistent direction (from line officers, etc.) means climate change is not prioritized in planning efforts

- Bureaucracy makes the process of getting any new ideas/actions implemented incredibly slow

\section{Example participant quotes}

- "Without extra resources in terms of capacity or funding, how are [resource managers] supposed to do [anything about climate change]."

- "The hardest thing is having the time to know all the latest, greatest science that's out there, and to have it readily available at your fingertips. We just don't have time to sit there and read everything."

- "[The USFS] still has an education job to do, particularly with folks on the forests and ranger districts, who are out there making these projects go, just to get them... tuned into considering [climate change]."

- "We're still kind of waiting for more of that top-down type of direction in terms of how we're supposed to consider and incorporate climate change into our forest planning efforts and effects analysis for projects."

- "...the Forest Service does not have a history of reacting to change very quickly." 